\title{
Seroprevalence of Human Cytomegalovirus Infection among Patients undergoing Chronic Hemodialysis in Benghazi, Libya
}

\author{
Farag Bleiblo ${ }^{1,4^{*}}$, Abdelhakim Eljaki ${ }^{1}$, Khaled Elwaheishi ${ }^{1}$, Mabroka Aljlale ${ }^{1}$, \\ Ata Alfalah ${ }^{1}$, Rabea Alghazal ${ }^{2}$ and Mohammed Abraheem ${ }^{3}$
}

${ }^{1}$ Department of Microbiology, Faculty of Science, University of Benghazi, Libya

${ }^{2}$ Immunology \& Virology Laboratory, Benghazi Children Hospital, Libya

${ }^{3}$ Department of Botany, Faculty of Arts and Science/Alkufra, University of Benghazi, Libya

${ }^{4}$ Department of Chemistry and Biochemistry and the Biomolecular Sciences Programme,

Laurentian University, Sudbury, ON, Canada, P3E 2 C6

*Corresponding author

\section{A B S T R A C T}

Keywords

CMV,

Hemodialysis, Seroprevalence, CMV-IgG, CMVIgM, CMV-pp65

Article Info

Accepted:

17 October 2019 Available Online: 10 November 2019
Human cytomegalovirus (HCMV) is a prominent opportunistic infectious agent causes severe and fatal diseases in immune compromised individuals including patients undergoing hemodialysis. Although the impact of HCMV infection in general population and patients at particular health care institutions are well documented in several regions, the seroepidemiologic data and overall awareness of disease risk of HCMV infection remain largely poor in Libya. Therefore, this study was undertaken to derive chronic hemodialysis-based estimates of HCMV prevalence. A total of 102 subjects admitted to the hemodialysis unit at Nephrology Center of Benghazi/Libya were enrolled in this study and investigated for CMV IgM and IgG antibodies as well as CMV pp65 antigenemia tests. The overall seropositivity for IgG antibodies (\% 26.47) was higher than those of IgM antibodies (\% 21.56) and pp65 (\% 17.64). CMV$\mathrm{IgG}$ was detected in a higher rate in females than that in males $(\% 27.58 \%$ and $\%$ 26.02 respectively). Similarly, the seroprevalence of CMV-IgM were also much higher in females $(\%$ 48.27) than that in male patients (\% 10.95). We also noticed a higher proportion of females were seropositive for CMV-pp65 (\% 20.68) than males (\% 16.43). However, there was no significant difference in the seroprevalence rates of CMV infection based on gender. According to age, a progressive increase in seropositivity of CMV was observed in all three tests performed on hemodialysis patients. However, the age groups were not significantly associated with CMV prevalence. In contrast, only 2 (\% 1.96) patients were shown to be positive for all three performed assays indicating a recurrent infection. In addition to the clinical significance of our findings for the management of CMV infection in hemodialysis patients, CMV infections in this setting may also improve our understanding of the viral pathogenesis. 


\section{Introduction}

Human cytomegalovirus (HCMV) is a ubiquitous virus infection distributed worldwide. This virus is the most common infectious cause of birth defects and congenital diseases, the most significant and difficult opportunistic pathogen affecting immune compromised patients, and an occasional cause of febrile illness as well as infectious mononucleosis (Cannon et al., 2010, Mocarski et al., 2014). HCMV infects an overwhelming majority of the population, transmitted efficiently throughout life and universally through contacts with bodily secretions. After the initial acquisition of HCMV, the virus replicates and causes a systemic infection, sometimes detected as a leukocyte-associated viremia, and disseminates to secretory organs such as salivary glands and kidney where replication produces virus found in secretions (Brooks et al., 2010). Viruses may be shed in any body fluids, including urine, saliva, tears, semen, and cervical secretions, and persistent shedding may continue for months to years, depending on age and immune status of the host (Brooks et al., 2010, Trkulic et al., 2000).

Like other human herpes viruses, HCMV is never completely cleared and remains latent for the life of the host. Persistently and sporadically shed virus is an important recurrent source of virus for transmission. Susceptibility to HCMV disease is associated with a compromised immune system, particularly related to defects in cell-mediated CD4 and CD8 T-cell functions (Mocarski et al., 2014). Despite potential antiviral drugs aimed to control the overall disease burden, the HCMV remains an important etiologic agent of opportunistic infections and disease in immune compromised individuals following organ transplantation and hematopoietic cell allografting, immunosuppressive therapies, and genetic or acquired immunodeficiency (Cannon et al., 2010, Cavlek et al., 2015, Mocarski et al., 2014).

Several studies have well established that hemodialysis patients have impaired immune response, which may result in higher prevalence rates of opportunistic infections, including HCMV (Betjes et al., 2007; Cavlek et al., 2015; Kao et al., 2002). Infection with HCMV in these patients is commonly due to reactivation of latent virus, re-infection with exogenous virus sources, which may be introduced by blood transfusion or kidney transplant, and initiation of primary infection through infected tissues and organs (Cordero et al., 2012).

Although much clinical and experimental progress has been made in identifying the implication of HCMV in chronic hemodialysis patients, the prevalence of HCMV infection among Libyans has remained largely unknown. Therefore, we investigated the seroprevalence of HCMV infection in patients undergoing chronic hemodialysis.

\section{Materials and Methods}

\section{Patient population}

One hundred two patients admitted to the hemodialysis unit at Nephrology Center of Benghazi/Libya during the one-year period were enrolled in this study. Informed consent was obtained from all patients and the protocol was approved by the Hospital's Ethics Committee. Demographic information including age, sex, marital status, literacy status, residential status, data about the onset of renal failure and hemodialysis history were obtained by means of referring to medical records and personal interviews. Throughout their tenure on the unit, a $5 \mathrm{ml}$ of blood was drawn from patients by vein puncture and placed in plastic disposable tubes; it was left 
to stand at room temperature $\left(20-25^{\circ} \mathrm{C}\right)$ to allow for clotting, then the sera was separated by centrifugation $10,000 \mathrm{rpm}$ for 5 minutes. Sera samples were stored at $-20{ }^{\circ} \mathrm{C}$ and later tested for cytomegalovirus antibodies by serological investigation.

\section{Detection of CMV IgG}

Microplate-based enzyme-linked immunoassay (ELISA) was used for the qualitative and quantitative detection of antiCMV IgG antibodies to cytomegalovirus in patients' sera according to the manufacturer's instructions (Autobio Diagnostics Co, LTD). The assay is based upon the two steps indirect enzyme immunoassay (EIA).

Briefly, in the first step, sample and recombinant CMV coated microwells are combined. During the incubation, the antiCMV antibodies present in the sample bind to the antigen coated in the wells. After the washing, in the second step enzyme-conjugate is added to the reaction mixture. The mouse anti-human IgG in the enzyme-conjugate is allowed to react with the anti-CMV IgG attached to the solid phase in the first step.

Then, a complex is generated between the solid phase, the anti-CMV IgG within the sample, and the mouse anti-human IgG in the enzyme conjugate. Then, the substrate $\mathrm{A}$ and substrate B are added and catalyzed by this complex. The resulting chromogenic reaction is measured in absorbance. The color intensity, which corresponds to the amount of CMV IgG antibodies present in the specimens, is measured with a microplate reader at $450 / 630 \mathrm{~nm}$ and the results were interpreted according to the manufacturer's instructions. Samples with optical densities $10 \%$ or more below the cutoff were recorded as negative, those with optical densities between 10\% below and $10 \%$ above the cutoff were equivocal, and all others were positive.

\section{Detection of CMV IgM}

To determine if the patients have acute or primary infection, serum samples were assayed for CMV-specific IgM using a CMV IgM ELISA (Autobio Diagnostics Co, LTD) and the results were interpreted according to the manufacturer's instructions. Samples giving an absorbance less than the cut-off value were considered negative for the presence of $\mathrm{CMV}$-specific IgM antibodies whereas those giving an absorbance equal to or greater than the cut-off value were considered reactively positive.

\section{Detection of CMV Antigenemia}

To quantitate the viral antigenemia, we performed Sandwich- ELISA to assay CMV lower matrix protein pp65 in patient's sera according to the manufacturer instructions (Sung long Biotech). The microtiter stripplate provided with this assay are precoated with antibodies specific to CMV pp65. Standards and samples were added to stripplate wells and combined to the specific antibody and then a horseradish CMV pp65 (HRP)conjugate specific for CMV pp65 was added to each microelisa stripplate well and incubated. The TMB substrate solution was added to each after washing away the free components. The wells containing the CMV pp65 and HRP-conjugated CMV pp65 antibody appeared blue and then turned yellow after adding the stop solution. The optical density (OD) was measured by microtiter plate reader at $450 \mathrm{~nm}$. The concentration of CMV pp65 in the sample was calculated by comparing the OD of the sample to the standard curve according to the manufacturer instructions.

\section{Results and Discussion}

One hundred two of chronic hemodialysis patients were followed during the course of 
the study. The median age of the patient population was $52( \pm 16.28)$ years. Our results revealed that only 27 (\% 26.47) out of these subjects were seropositive for CMV-IgG, while 22 (\% 21.56) patients were seropositive for CMV-IgM indicating a recent infection. Based on the laboratory diagnosis of CMVpp65, we determined that 18 (\% 17.64) patients had CMV viremia as indicated in Table 1. Only two (\% 1.96) patients were shown to be positive for all three performed assays indicated the presence of recurrent infection.

Cytomegalovirus is considered as one of the most encountered opportunistic viral pathogens distributed universally among human population affecting particularly immune compromised patients including hemodialysis patients. Generally, patients on hemodialysis have impaired immune system due to multiple transfusions and low lymphocyte count. Various defects in the $\mathrm{T}$ cell function of these patients had been described which might be due to intrinsic $T$ cell abnormality rather than due to hemodialysis (Van Riemsdijk et al., 2003). Several epidemiological studies on seroprevalence of HCMV infection in hemodialysis patients has been published. Previous studies conducted in some European regions showed a significantly higher CMV seropositivity among hemodialysis patients comparing to the healthy control group (Betjes et al., 2007; Korcáková et al., 2000; Korcáková et al., 1988; Sibrowski et al., 1990; Trkulic et al., 2000). A higher CMV prevalence in hemodialysis patients could be explained by exposing to risk factors such as the acquisition of CMV through repeated blood transfusions or exposure to CMV during hemodialysis procedures. The Seroepidemiologic variation in the prevalence of HCMV infection may rely on convenience samples from patients at a particular health institution, geographical distribution and sensitivity of different assays used for defection of CMV antibodies. In this study we enrolled 73 males and 29 females' participants. The overall seropositivity of CMV in hemodialysis patients were slightly higher in females than in males (Table 2). CMV-IgG antibodies were detected in 19 (\%26.02) males and 8 (\%27.58) females. The seroprevalence of $\mathrm{CMV}-\mathrm{IgM}$ were much higher in females $(\%$ 48.27) than that in male patients (\% 10.95). We noticed a higher proportion of females were seropositive for CMV-pp65 (\% 20.68) than males (\% 16.43). However, there was no significant difference in the seroprevalence rate of CMV infection based on gender ( $p>0.05)$.

Several lines of evidence including both genders consistently reported prevalence rates that are slightly higher in women than in men. Population-based evaluation of HCMV prevalence that have been derived from the National Health and Nutrition Examination Survey (NHANES), starting with a 1988 to 1994 set and continuing with 1999 to 2004 set (6 years of age or older) estimated that more female patients $(63.5 \%)$ than male $(54.1 \%)$ were infected (Bate et al., 2010,Staras et al., 2006). In agreement with our findings, a study by Cavlek et al., (2015) reported that there were no differences in CMV prevalence between males and females.

Furthermore, de Matos et al., (de Matos et al., 2011)foundnon- significant relation concerning sex status of the CMV prevalence. In addition, previous reports by Salman et al., in Iraq (Salman et al., 2014) and Cannon et al., (2010) in U.S. demonstrated that females had higher seroprevalence than males. The gender variation in CMV prevalence may reflect that females are more exposed to young children. The higher titers of CMV in urine and/or saliva presumably attributed to CMV infection during childcare. 
Table.1 Prevalence of CMV-IgG, CMV-IgM, and CMV-pp65 Antibodies in Hemodialysis Patients

\begin{tabular}{|c|c|c|c|c|c|c|}
\hline \multirow{2}{*}{$\begin{array}{c}\text { Total No. of } \\
\text { Patients }\end{array}$} & \multicolumn{2}{|c|}{ CMV-IgG } & \multicolumn{2}{c|}{ CMV-IgM } & \multicolumn{2}{c|}{ CMV-pp65 } \\
\cline { 2 - 7 } & No & $\%$ & No & $\%$ & No & $\%$ \\
\hline $\mathbf{1 0 2}$ & 27 & 26.47 & 22 & 21.56 & 18 & 17.64 \\
\hline
\end{tabular}

Table.2 Distribution of CMV- IgG, CMV-IgM, and CMV-pp65 Antibodies According to Gender

\begin{tabular}{|c|c|c|c|c|c|c|c|}
\hline \multirow[t]{2}{*}{ Gender } & \multirow{2}{*}{$\begin{array}{c}\text { No. of } \\
\text { Patients }\end{array}$} & \multicolumn{2}{|c|}{ CMV-IgG } & \multicolumn{2}{|c|}{ CMV-IgM } & \multicolumn{2}{|c|}{ CMV-pp65 } \\
\hline & & No & $\%$ & No & $\%$ & No & $\%$ \\
\hline Male & 73 & 19 & 26.02 & 8 & 10.95 & 12 & 16.43 \\
\hline Female & 29 & 8 & 27.58 & 14 & 48.27 & 6 & 20.68 \\
\hline Total & 102 & 27 & 26.47 & 22 & 21.56 & 18 & 17.64 \\
\hline & $\mathbf{P}$ & \multicolumn{2}{|c|}{$>0.05$} & \multicolumn{2}{|c|}{$>0.05$} & \multicolumn{2}{|c|}{$>0.05$} \\
\hline
\end{tabular}

Table.3 Distribution of CMV- IgG, CMV-IgM, and CMV-pp65 Antibodies According to Age Groups

\begin{tabular}{|c|c|c|c|c|c|c|c|}
\hline \multirow{2}{*}{$\begin{array}{c}\text { Age } \\
\text { Group }\end{array}$} & \multirow{2}{*}{$\begin{array}{c}\text { No. of } \\
\text { Patients }\end{array}$} & \multicolumn{2}{|c|}{ CMV-IgG } & \multicolumn{2}{|c|}{ CMV-IgM } & \multicolumn{2}{|c|}{ CMV-pp65 } \\
\hline & & No & $\%$ & No & $\%$ & No & $\%$ \\
\hline$<30$ & 7 & 1 & 14 & 3 & 42.85 & 1 & 14 \\
\hline $30-44$ & 36 & 9 & 25 & 8 & 22 & 6 & 16.66 \\
\hline $45-59$ & 35 & 10 & 28.57 & 8 & 22.85 & 8 & 22.85 \\
\hline$\geq 60$ & 24 & 7 & 29.16 & 3 & 13 & 3 & 13 \\
\hline Total & 102 & 27 & 26.47 & 22 & 21.56 & 18 & 17.64 \\
\hline \multicolumn{2}{|c|}{$\mathbf{P}$} & \multicolumn{2}{|c|}{$>0.05$} & \multicolumn{2}{|c|}{$>0.05$} & \multicolumn{2}{|c|}{$>0.05$} \\
\hline
\end{tabular}

However, it has been suggested that adolescent males are similar to females at a higher risk of CMV infection when exposed to young children in the household (Stadler et al., 2010).

According to the age-related prevalence of CMV infection, the highest rate of CMV-IgG antibodies was detected within the age group $\geq 60$ years (\% 29.16) followed by those located within the age group 45-59 years (\% 28.57) as indicated in Table 3 . Regarding the IgM seropositivity, we found that the age group younger than 30 years of old had the highest rate $(\%$ 42.85) followed by those within the age group 45-59 years (\% 22.85). similarly, the highest CMV-pp65 positivity rate was determined within the age group 4559 (\% 22.85) followed by those patients located with the age group 30-44 (\%16.66). Although, CMV seroprevalence did not differ significantly between age groups ( $p>0.05)$.

Although prevalence of CMV infection increases with age in many age groups that have been studied, the overall prevalence of infection and the age at initial acquisition of virus vary greatly according to living circumstances and socioeconomic status. In general, prevalence of infection is greater, and virus is acquired earlier in life in developing countries compared to the United States and Europe, where prevalence is greater in the lower socioeconomic strata, among nonwhites, 
and in immigrant populations from developing countries (Grifiths et al., 1984, Stadler et al., 2010). Based on a large samplings study derived from NHANES, it has been shown that the overall age-adjusted prevalence of HCMV infection in the United States remains about $59 \%$, with about one-half of the U.S. population aged 6 to 49 infected (Bate et al., 2010, Staras et al., 2006). This study reported that the age-related prevalence of HCMV infection was greater within groups aged greater than 49 years. In accordance with our study, Cavlek et al., (2015) have observed a progressive increase in seroprevalence with age both hemodialysis patients and controls. However, they showed that age was a significant risk factor for CMV seropositivity. Age-related increase in the seroprevalence of CMV antibodies has also been reported in many other studies (Ikram, 1981; Kao et al., 2002; Korcáková et al., 1988; Ocak et al., 2006; Spisni et al., 1992).

Since reinfection and reactivation may cause life-threatening diseases in hemodialysis patients, detection of the virus as well as the demonstration that HCMV is associated with diseases become essential. In addition to the clinical importance of HCMV in the management of hemodialysis patients, our results may also improve our understanding of the viral pathogenesis.

\section{References}

Bate SL, Dollard SC, Cannon MJ. Cytomegalovirus seroprevalence in the United States: the national health and nutrition examination surveys, 19882004. Clin Infect Dis 2010; 50(11): 1439-1447.

Betjes MG, Litjens NH, Zietse R. Seropositivity for cytomegalovirus in patients with end-stage renal disease is strongly associated with atherosclerotic disease. Nephrol Dial Transplant 2007; 22: 3298-303.

Brooks, G.F., Carroll, K.C., Butel, J.S., Morse, S.A. and Mietzner, T.A. 2010. Jawetz, Melnick and Adelberg's Medical Microbiology. 25th ed. McGraw-Hill companies. Inc. United States of America. pp: 467-488.

Cannon, M.J., Schmid, D.S. and Hyde, T.B. 2010. Review of cytomegalovirus seroprevalence and demographic characteristics associated with infection. Rev Med Virol, 20(4), pp: 202-213.

Cavlek, T., Kolaric, B., Sternak, S., Kos, M., Kaic, B. and Galinovic, G. 2015. Prevalence and dynamics of Cytomegalovirus infection among patients undergoing chronic hemodialysis. Indian J. Nephrol, 25(2), pp: 95-98.

Cordero E, Casasola C, Ecarma R, Danguilan R. Cytomegalovirus disease in kidney transplant recipients: Incidence, clinical profile, and risk factors. Transplant Proc 2012; 44:694-700.

de Matos, S.B., Meyer, R. and Lima, F.W. 2011. Seroprevalence and serum profile of cytomegalovirus infection among patients with hematologic disorders in Bahia State, Brazil. J Med Virol, 83(2), 298-304.

Grifiths PD, Baboonian C. A prospective study of primary cytomegalovirus infection during pregnancy: inal report. BJOG 1984; 91:307-315.

Ikram H. Cytomegalovirus infections in hemodialysis centers. Clin Nephrol $1981 ; 15: 1-4$.

Kao TW, Hsu WA, Chen HS, Chen WY. A two-year follow-up study of common virus infections in hemodialysis patients in Taiwan. Artif Organs 2002; 26:879-83.

Korcáková L, Jovanovic D, Ostojic G, Kovacevic Z, Taseski J. Cytomegalovirus infection in patients 
with kidney diseases. Vojnosanit Pregl 2000;57:63-7.

Korcáková L, Kaslík J, Svobodová J, Kaslíková J, Bláha J, Sedlácková E, et al., CMV infection in patients with chronic renal failure and in those following transplantation. Czech Med 1988;11:131-6.

Mocarski, ES, Shenk, Griffiths PD, Pass RF: Cytomegaloviruses. In : David M. Knipe and Peter M. Howley. Field Virology, $6^{\text {th }}$ ed. Lippincott Williams \& Wilkin, 2013, 1960-2014

Ocak S, Duran N, Eskiocak AF. Seroprevalence of cytomegalovirus antibodies in hemodialysis patients. Turk J Med Sci 2006; 36:155-8

Saadoon IH, Frequency of CMV- Infection among Hemodialysis Patients in Tikrit City, Iraqi Journal of Science, 2015, Vol 56, No.3C, pp: 2523-2528

Salman AD, Alsaadi LA, and ALazi IH. Seroprevalence of human cytomegalovirus among hemodialysis patients in Diayala province, Int.J.Curr.Microbiol.App.Sci (2014) 3(12): 160-165

Sibrowski W, Kühnl P, Kalmar G, Albert S, Böhm BO, Doerr HW. Cytomegalovirus diagnosis in blood donors and risk patients. BeitrInfusionsther 1990;26:37-9.

Spisni C, Stingone A, Di Vito R, Rondinella I, D'Amario C, Tucci E, et al., Serum epidemiological trial on the prevalence of the anti-cytomegalovirus antibodies in patients under substitutive treatment with hemodialysis and CAPD. Nephron 1992;61:373-4.

Stadler, L.P,. Bernstein, D.I., Callahan, S.T. et al., 2010. Seroprevalence of Cytomegalovirus (CMV) and risk factors for infection in adolescent males. Clin Infect Dis, 51 (10), pp: e76-e81.

Staras SA, Dollard SC, Radford KW, et al., Seroprevalence of cytomegalovirus infection in the United States, 19881994. Clin Infect Dis 2006; 43(9):11431151.

Trkulic, M., Jovanovic, D., Ostojic, G., Kovacevic, Z. and Taseski, J. 2000. Cytomegalovirus infection in patients with kidney diseases. Vojnosanit Pregl, 57(5), pp: 63-67.

Van Riemsdijk, I., et al., Patients on chronic hemodialysis have no intrinsic lymphocyte defect upon stimulation with interleukin-2, interleukin-15 or tumor necrosis factor-alpha. Blood purification, 2003. 21(2): p. 158-162.

\section{How to cite this article:}

Farag Bleiblo, Abdelhakim Eljaki, Khaled Elwaheishi, Mabroka Aljlale, Ata Alfalah, Rabea Alghazal and Mohammed Abraheem. 2019. Seroprevalence of Human Cytomegalovirus Infection among Patients undergoing Chronic Hemodialysis in Benghazi, Libya. Int.J.Curr.Microbiol.App.Sci. 8(11): 1979-1985 doi: https://doi.org/10.20546/ijcmas.2019.811.231 